\title{
Medicine Goes Politics?
}

\author{
Felix J.F. Herth \\ University of Heidelberg, Heidelberg, Germany
}

Populations have changed a lot in the last few decades and will continue to change. At the end of $2005,20 \%$ of the German population was younger than 20 years, while those aged $\geq 65$ accounted for $19 \%$. The remaining $61 \%$ were persons of working age $(20$ to $<65)$. By contrast, only half of the German population will be of this working age in 2050 , over $30 \%$ will be $\geq 65$ years and about $15 \%$ will be under 20 years old [1].

The associated age-related increase in chronic diseases, in physical and cognitive limitations, in falls, and in multimorbidities requires special care needs for older people [2].

On the other hand, diseases are as different as humans are. In order to establish these differences, more and more analytic procedures and personalized information are being gathered. Patients who appear to have the same clinical picture still react differently to therapies and medications. This direction, also known as "personalized" medicine, attempts to decipher the molecular differences of diseases and to develop appropriate drugs. The treatment options for lung cancer patients [3] as well as interventional procedures [4] clearly show such developments.

Such changes are also developmental opportunities: the aging population, medical progress, and the increasing health awareness of the population represent enormous growth potential. In this "growth health market," research-based pharmaceutical manufacturers represent a future-oriented and subsidy-free high-tech industry, which makes contributions to the solution in various fields.

For example, this area has now become the most important economic factor in Germany. A study from 2009, commissioned by the Federal Ministry of Economics, speaks of currently 5.3 million employees, who work in the broadest sense in the field of health and generate a total turnover of EUR 278 billion annually [5].

The pharmaceutical industry is an important part of the healthcare industry and contributes significantly to the creation of jobs and economic values in other industries through economic "leverage." The healthcare industry as well as the number of healthcare providers is currently growing.

Ultimately, healthcare is becoming more and more expensive. Patients with chronic diseases can survive longer and longer with better and increasingly more expensive medications or technical innovations. But who is paying the bill?

Various health systems exist worldwide. The variable importance of state, social, and private actors in the individual systems has led to a division into 3 ideal types of health systems. The first type is the public health service, which provides funding through taxes, provides services through public utilities, and sets the rules of the system through the actors of the state or policy [6].

\section{KARGER}

(C) 2017 S. Karger AG, Basel
Felix J.F. Herth

Pneumology and Critical Care Medicine

Thoraxklinik, University of Heidelberg

Röntgenstr. 1, DE-69126 Heidelberg (Germany)

E-Mail felix.herth@med.uni-heidelberg.de 
By contrast, the state plays a weaker role in the second type: the social security system. Financing is governed by social security systems, which are used, for example, by companies and their employees, as is the case in Germany. The lesser importance of the state is also reflected in the provision of services, where private-sector actors operate alongside public providers. The regulation of social security systems is characterized by the fact that the non-state actors can shape their relationships to a certain extent on their own initiative (self-administration principle).

Finally, private or private sector systems are the third type. In private systems, the state largely withdraws from the financing, organization, and management of the health system, leaving these tasks to private actors. Financing is handled predominantly via private insurance and household expenditure. Supply is based on private providers competing with other service providers, and the regulation of the system is to a large extent left to the mechanisms of the market [6].
However, in all 3 systems, somebody has to make decisions. Those drivers stem mostly from politics or have an economic background with much or little medical knowledge. This may lead to an influential takeover of medical decisions by the drivers instead of us. But looking back at our roots, already in the Hippocratic oath, it is stated "I will use treatment to help the sick according to my ability and judgment, ...”. Following this oath is not always possible depending on the healthcare system which is in place [7].

However, this means that as treating physicians we also have to be politically involved. It requires the active participation in decision making to ensure that not purely economic considerations are to dictate our options and possibilities. This can be done through professional societies, patient associations, or individual measures. But the time of being passive in relation to health issues is over. Medicine must become more political, otherwise we lose the necessary control.

\section{References}

1 https://www.destatis.de/EN/FactsFigures/ SocietyState/Population/PopulationProjection/PopulationProjection.html.

2 GBD 2013 Mortality and Causes of Death Collaborators: Global, regional, and national age-sex specific all-cause and cause-specific mortality for 240 causes of death, 1990-2013: a systematic analysis for the Global Burden of Disease Study 2013. Lancet 2015;385:117171.
3 Arnedos M, Soria JC, Andre F, Tursz T: Personalized treatments of cancer patients: a reality in daily practice, a costly dream or a shared vision of the future from the oncology community? Cancer Treat Rev 2014;40:11921198.

4 Pietzsch JB, Garner A, Herth FJ: Cost-effectiveness of endobronchial valve therapy for severe emphysema: a model-based projection based on the VENT Study. Respiration 2014; 88:389-398.
5 https://www.goinginternational.eu/newsletter/2013/nl_03/SpecialDE_EN_Understanding the German.pdf.

6 https://www.bpb.de/politik/innenpolitik/gesundheitspolitik/72906/gesundheitswesenim-europaeischen-vergleich.

7 https://en.wikipedia.org/wiki/Hippocratic_ Oath. 